\title{
A RELAÇÃO TEORIA E PRÁTICA NA FORMAÇÃO DOCENTE: CONDIÇÃO ESSENCIAL PARA O TRABALHO PEDAGÓGICO
}

\section{LA RELACIÓN TEORÍA Y PRÁCTICA EN LA FORMACIÓN DOCENTE: CONDICIÓN PARA EL TRABAJO PEDAGÓGICO}

\section{THE RELATIONSHIP THEORY AND PRACTICE IN TEACHING TRAINING: ESSENTIAL CONDITION FOR PEDAGOGICAL WORK}

\author{
Marta Silene Ferreira BARROS ${ }^{1}$ \\ Jaqueline Delgado PASCHOAL ${ }^{2}$ \\ Dayanne VICENTINI ${ }^{3}$ \\ Jacqueline Daniele FRANÇA DE ALMEIDA ${ }^{4}$ \\ Ana Letícia FERREIRA ${ }^{5}$ \\ Priscila Cordeiro Soares BARROS ${ }^{6}$
}

RESUMO: A formação docente se apresenta como um dos desafios na contemporaneidade. A proposta deste estudo busca discutir a relação teoria e prática na formação como elemento essencial para o desenvolvimento do trabalho pedagógico. A partir disso, objetiva-se analisar de que modo a dicotomia ou a unidade teoria e prática pode influenciar na formação do professor. Trata-se de uma pesquisa qualitativa, subsidiada pela abordagem crítico-dialética a partir dos pressupostos de uma educação emancipadora, que enxerga a formação como um aspecto de educação para a humanização e emancipação do sujeito. Optou-se pela revisão bibliográfica com o propósito de compilar sua base teórica. As perspectivas apontadas se justificam pela premência de refletir os processos de formação do educador, no sentido de possibilitar uma visão diferenciada que contribua para ações educativas no atual contexto social, visando o desenvolvimento humano para além das demandas utilitárias do mercado. Conforme as tendências estudadas no âmbito desta análise avalia-se que nos cursos de formação de professores faz-se iminente a superação da dissociação entre conteúdo e forma, teoria e prática, elementos que constituem-se num dos dilemas dos programas formativos. Com isso, se pretende contribuir para que docentes, professores e futuros professores possam

\footnotetext{
${ }^{1}$ Universidade Estadual de Londrina (UEL), Londrina - PR - Brasil. Professora Associada do Departamento de Educação e do Programa de Pós-Graduação em Educação. OrcID: https://orcid.org/0000-0002-1924-8490. Email: mbarros_22@hotmail.com

${ }^{2}$ Universidade Estadual de Londrina (UEL), Londrina - PR - Brasil. Professora Associada do Departamento de Educação e do Programa de Pós-graduação em Educação. OrcID: https://orcid.org/0000-0002-7961-2362. Email: jaquelinedelgado@uol.com.br

3 Universidade Estadual de Londrina (UEL), Londrina - PR - Brasil. Mestrado em Educação. OrCID: https://orcid.org/0000-0003-2086-1951. E-mail: dayannevicentini@ hotmail.com

${ }^{4}$ Universidade Estadual de Londrina (UEL), Londrina - PR - Brasil. Mestranda em Educação. OrcID: https://orcid.org/0000-0002-0422-4533. E-mail: jacque.daniele@yahoo.com.br

5 Universidade Estadual de Londrina (UEL), Londrina - PR - Brasil. Mestranda em Educação. OrcID: https://orcid.org/0000-0003-1321-6911. E-mail: leticiavieira1995@ hotmail.com

6 Universidade Estadual de Londrina (UEL), Londrina - PR - Brasil. Mestranda em Educação. OrcID: https://orcid.org/0000-0003-4074-2714. E-mail: pbarros18@gmail.com
} 
repensar a formação de sujeitos críticos em que a finalidade seja pensar a formação de maneira contínua.

PALAVRAS-CHAVE: Educação. Teoria e prática. Formação docente. Trabalho pedagógico.

RESUMEN: La formación docente se presenta como uno de los desafíos en la contemporaneidad. La propuesta de este estudio busca discutir la relación teoría y práctica en la formación como elemento esencial para el desarrollo del trabajo pedagógico. A partir de eso, se objetiva analizar de qué modo la dicotomía o la unidad teoría y práctica puede influenciar en la formación del profesor. Se trata de una investigación cualitativa, subsidiada por el enfoque crítico-dialéctico a partir de los presupuestos de una educación emancipadora, que ve la formación como un aspecto de educación para la humanización y emancipación del sujeto. Se optó por la revisión bibliográfica con el propósito de compilar su base teórica. Las perspectivas apuntadas se justifican por la premura de reflejar los procesos de formación del educador, en el sentido de posibilitar una visión diferenciada que contribuya a acciones educativas en el actual contexto social, visando el desarrollo humano más allá de las demandas utilitarias del mercado. Conforme a las tendencias estudiadas en el marco de este análisis se evalúa que en los cursos de formación de profesores se hace inminente la superación de la disociación entre contenido y forma, teoría y práctica, elementos que se constituyen en uno de los dilemas de los programas formativos. Con ello, se pretende contribuir para que docentes, profesores y futuros profesores puedan repensar la formación de sujetos críticos en que la finalidad sea pensar la formación de manera continua.

PALABRAS-CLAVE: Educación. Teoría y práctica. Formación docente. Trabajo pedagógico.

ABSTRACT: Teacher training presents itself as one of the challenges in the contemporaneity. The purpose of this study is to discuss the relationship between theory and practice in education as an essential element for the development of pedagogical work. From this we aim to analyze how the dichotomy or the unit theory and practice can influence the formation of the teacher. It is a qualitative research, subsidized by the critical-dialectic approach based on the presuppositions of emancipatory education, in which it sees formation as an aspect of education for the humanization and emancipation of the subject. We choose for the bibliographic review with the purpose of compiling its theoretical basis. The perspectives pointed out are justified by the need to reflect the educator's training processes, in order to allow a differentiated vision that contributes to educational actions in the current social context, aiming human development beyond the utilitarian demands of the market. According to the tendencies studied in the scope of this analysis it is evaluated that in teacher training courses it is necessary to overcome the dissociation between content and form, theory and practice, elements that constitute one of the dilemmas of the training programs. With this, it is intended to help professor, teachers and future teachers to rethink the formation of critical subjects in which the purpose is to think about training in a continuous way.

KEYWORDS: Education. Theory and practice. Teacher training. Pedagogical work. 


\section{Introdução}

Constata-se na atualidade, a recorrente presença da temática "formação de professores" em pesquisas e eventos educacionais e o destaque atribuído ao processo formativo. $\mathrm{O}$ referido tema se vincula às discussões acerca da problemática que envolve o trabalho pedagógico, o qual está relacionado ao incremento qualitativo da educação no Brasil. A partir dessa compreensão afirma-se que existe um vínculo de dependência entre a qualificação de professores e a melhoria do ensino. Entretanto, os saltos qualitativos que sobrevém à educação brasileira não podem ser analisados exclusivamente sob essa ótica, atribuindo-se todos os determinantes desse processo unicamente à formação dos professores. A apreensão desse fenômeno requer a ampliação do olhar para o que se encontra além dos muros da escola e que pode impactar o sistema educativo como os aspectos: históricos, políticos, econômicos e sociais.

É importante ressaltar que a busca pela qualidade para o ensino conhecidamente defendida pela proposta neoliberal, que associa as lacunas na formação dos professores como um fator que coaduna com níveis baixos de qualidade, acaba por reduzir a educação a mera instrumentalização enquanto desconsidera outros aspectos da realidade, tais como: condições de trabalho, salários, qualificação, reconhecimento profissional, descentralização de poderes tanto pedagógicos quanto financeiros, além de políticas educacionais descontinuadas, seletivas e excludentes. Este tipo de qualificação se enquadra no modelo denominado por Freitas (1992) de neotecnicismo ainda vigente nos dias atuais.

Consequentemente, a prática pedagógica do professor encontra-se inserida num contexto social, mais especificamente, dentro de uma organização escolar que reflete a divisão social do trabalho e as contradições advindas desse complexo marcado pelos princípios que norteiam a proposta de uma política neoliberal. Nesse panorama, a universalização do ensino, prerrogativa da referida propositura deve considerar que ao ampliar a quantidade de crianças na escola a estrutura educacional também poderá acompanhar essa ampliação a fim de manter a qualidade da educação oportunizada.

É relevante salientar que com o sistema de educação, ampliado quantitativamente, a necessidade de formar professores se revela urgente. Com isso, a demanda por cursos de formação aumentou e com ela o surgimento de uma infinidade de cursos aligeirados, sem aprofundamento teórico e, sobretudo sem atividades de pesquisa e extensão. A partir disso, infere-se que o educador formado pelos referidos cursos, não tem a oportunidade de vivenciar todas as dimensões do conhecimento na academia. Privilegiam-se algumas áreas do 
conhecimento em detrimento de outras, o que pode ser interpretado como um modelo de educação utilitarista, contrária à ideia de formar professores aos quais caberá mediar o conhecimento às futuras gerações.

Considerando o cenário atual é relevante destacar que a qualificação dos profissionais da educação constitui-se em uma preocupação pertinente na busca de alternativas que propiciem o refinamento do trabalho educativo na organização escolar. Não obstante, neste estudo negamos a qualificação de professores que envolva apenas cursos de reciclagens, alheios à prática do professor e à dinâmica da sala de aula. Diante disso, a formação em serviço ou formação em contexto pode representar uma possibilidade promissora, especialmente para os professores que não tem outras oportunidades de formação fora do seu ambiente de trabalho.

Diante da complexidade da questão, deter-nos-emos na análise de alguns aspectos que influenciam a formação do educador, como a organização curricular do curso, a formação de professores na contemporaneidade, bem como a formação do professor como subsídio para mediação do conhecimento e o processo indissociável ensino-aprendizagem, que envolve a relação professor-aluno (mediação), aluno-aluno, professor-conhecimento e alunoconhecimento, tendo como eixo norteador desta reflexão a relação entre teoria e prática.

\section{O dilema dos cursos de formação de professores quanto à organização curricular}

A organização curricular dos cursos de formação de professores na sua grande maioria é composta pela formação acadêmica e a formação pedagógica. A primeira oportuniza conhecimentos que possibilitam a apreensão dos conteúdos curriculares específicos da área de conhecimento, e respectivamente, a formação pedagógica, que na maioria das vezes se volta para estudos acerca do desenvolvimento de capacidades metodológicas para mediar os conteúdos no processo de ensino. O grande desafio é encontrar o equilíbrio para conciliar estas duas dimensões que compõem os cursos de formação.

Pesquisadores brasileiros que abordam essa temática têm revelado que o modelo dominante da organização curricular dos cursos de formação de professores fundamenta-se no agrupamento das disciplinas do "bloco teórico" do início do curso, ficando para o final as disciplinas do "bloco prático". Em outras palavras, primeiro se oferece a informação básica de conhecimentos gerais, e, de posse desses conteúdos, o aluno passa ter a formação pedagógica que o habilitará ao exercício da docência. (SAVIANI, 2009). 
Sobre essa problemática, podemos observar que a base intelectual do professor é essencial para o desenvolvimento da sua atividade de ensino, contudo, avalia-se que os conhecimentos que a constituem não podem estar desprovidos dos significados educativos e de seus fundamentos sócio-históricos. Na perspectiva de Saviani (2009, p.151), “[...] a dissociação se deu por um processo de abstração, para recuperar a indissociabilidade será necessário considerar o ato docente como fenômeno concreto, isto é, tal como ele se dá efetivamente no interior das escolas".

O que constata-se nos modelos de formação vigentes é que apenas algumas disciplinas do currículo têm a finalidade de pensar a prática docente. Esse tipo de preparação de professores revela que "aprender a ser professor" consiste em uma tarefa fácil que se desenvolve de maneira rápida e aligeirada. Porém a experiência acadêmica no curso de Pedagogia demonstra que a prática de ensinar do professor não é "construída" de um momento para o outro, como num "passe de mágica”. É, sim, um processo que demanda tempo e exige uma relação dialética entre as disciplinas do curso. Tendo como parâmetro o pensamento de Kosik (1995, p.20), entende-se que a dialética é "[...] o pensamento crítico que se propõe a compreender a 'coisa em si' e sistematicamente se pergunta como é possível chegar à compreensão da realidade".

Outro ponto relevante a destacar na análise acerca da formação de professores é o status de superioridade conferido à teoria em relação à prática, o que demonstra a concepção de educação imbuída na sua organização. Nesse cenário as disciplinas que se ocupam com a preparação prática dos professores são consideradas menos relevantes, como por exemplo, a Prática de Ensino e os Estágios Supervisionados. Sobre essa situação verificamos que há um entendimento equivocado do significado de teoria e de prática, pois, a teoria não existe fechada em si mesma, como autossuficiente, pelo contrário ela se elabora e reelabora por meio da prática no movimento dialético.

É a práxis que precisa fazer parte da atividade do professor, já que ela é indissociável do ato educativo, o qual segundo Saviani (1997, p. 13) consiste em [...] produzir, direta e intencionalmente, em cada indivíduo singular, a humanidade que é produzida histórica e coletivamente pelo conjunto dos homens". Sendo a prática educativa parte indissociável da atividade do professor, Vázquez (1968) em seus estudos acerca da filosofia da Práxis concebe um valor à prática evidenciando que ela é fundamento, finalidade e critério de verdade da teoria.

É mister destacar que na organização do conhecimento - em disciplinas teóricas e práticas - nos cursos de formação de professores, está implícito o entendimento acerca do 
binômio teoria-prática, seja para a dicotomia ou unidade. A forma como o curso está organizado na maioria das vezes constitui-se em uma estratégia didática para trabalhar com os conhecimentos das diferentes áreas do saber - divisão em disciplinas. No entanto, o que se intenta ressaltar é que a operacionalização do trabalho pedagógico, dos conteúdos das diferentes disciplinas que compõem o curso, revela um distanciamento da realidade educacional. Podemos constatar essa questão nas disciplinas ofertadas nos cursos, os quais em sua maioria, realizam pesquisas de contemplação sobre a escola, idealizando e definindo, a priori, as características dessa instituição. Podemos considerar que estes estudos não privilegiam a escola com sua complexidade, ao contrário, distanciam-se da real situação que envolve o ambiente escolar, em que o valor dos estudos de cada disciplina torna-se um fim em si mesmo.

O que se observa é a prática do professor sendo desenvolvida por automatismos aprendidos e reproduzidos durante a sua vida estudantil e profissional, excluindo-se a crítica desse processo. É necessário discutir a concepção que permeia os espaços da escola de que a "prática se faz na prática", incluindo-se nesse processo as ações espontâneas, desvinculadas de objetivos pré-definidos e finalidades planejadas para o ensino. Esse modelo de formação sugere que o professor seja um mero transmissor de conhecimentos. A proposta de estudo aqui apresentada nega essa forma de pensar a formação e a prática do professor, pois, na perspectiva que preconiza esse trabalho, a concepção de formação é entendida como uma atividade humana que busca a transformação do mundo natural, social e humano. Essa atividade contém dimensões que se relacionam com a apropriação do conhecimento atividade de caráter teórico - e às vinculadas ao transformar, à ação e à objetivação atividade prática. Nessas circunstâncias o professor desempenha a função de mediador do conhecimento na relação que estabelece com sua atividade de ensino visando a aprendizagem e o desenvolvimento do sujeito.

Perante o exposto, é mister evidenciar que uma prática desprovida de teoria torna-se uma prática vazia, sem direcionamento, causando sérios obstáculos à realização do ensino. Vários são os exemplos que podem confirmar tal situação, dentre os quais: o apego dos professores aos modismos teóricos, a aceitação sem oposição das propostas governamentais e, o mais clássico, a dependência destes profissionais para com o livro didático, tornando este instrumento o principal condutor do processo pedagógico, (de)formando a função do professor. Assim, diante dos dilemas que os cursos de formação de professores apresentam em sua organização curricular é importante pensar formas de superação dos modelos presentes em que a formação do sujeito integral seja o maior objetivo. 


\section{A formação de professores na contemporaneidade}

A formação de professores, como não poderia deixar de ser, também segue alguma lógica, ideologia, e/ou programa dependendo do tipo ou do perfil de professor que se deseja formar. Os programas de formação podem ter como foco a formação da consciência, para além da formação com caráter apenas instrumental.

Nesse sentido, urge compreender quais elementos podem formar o professor que não apenas saiba executar o seu trabalho educativo, mas que compreenda todas as suas dimensões enquanto "atividade eminentemente humana", ou seja, parte do "processo da educação, que tem como meta final a formação integral do homem” (GASPARIN, 2002, p.28). Essa é uma lógica que vai além do formar o educador para atender às demandas do sistema econômico vigente, mas almeja a formação humana do sujeito. Sob a ótica de Martins e Duarte (2010, p.14, grifo do autor),

[...] nenhuma formação pode ser analisada senão na complexa trama social da qual faz parte. Ao assumirmos a referida prática como objeto de análise, observando que não estamos nos referindo à "prática" de sujeitos isolados, mas à prática do conjunto dos homens num dado momento histórico, deparamos com uma tensão crucial: a contradição entre o dever ser não pode prescindir da luta pela superação das condições que lhe impõe obstáculos.

Como tal, as tendências de formação de professores sofrem influências que não são imparciais, ou melhor, apresentam um posicionamento, ainda que implícito, que tanto pode negar quanto coadunar com a ideologia dominante. Por essa razão, ao analisar uma pesquisa, artigo, produção acerca de formação, o olhar requer um aprofundamento da questão, para além das suas aparências.

Segundo Silva (2014, p.91) é necessário ter um olhar crítico em relação à formação que se deseja ofertar para não cair no discurso "da perspectiva da ideologia neoliberal, em que não há muito que se preocupar com a formação dos licenciados, do futuro professor que atuará na formação dos estudantes do ensino básico". É preciso analisar nas entrelinhas das ideias que permeiam a formação de professores para entendermos que alguns teóricos, mesmo com um discurso de formação que equilibre e integre teoria e prática, na realidade por trás priorizam as questões práticas em detrimento das teóricas.

De acordo com Saviani (2009), nos cursos de formação de professores é preciso superar a dissociação entre conteúdo e forma, pois esse é um dos dilemas enfrentados nos 
programas de formação. Nessa perspectiva é possível inferir que se torna basilar articular essas duas categorias nas ações pedagógicas, a fim de atingir a qualidade nos processos de formação. "Qualidade" de acordo com os objetivos educacionais propostos, com vistas à emancipação e humanização.

Martins (2015, p.134) afirma que o grau de alienação do educador diminui à medida em que ele consegue "apropriar-se das objetivações genéricas para si e estabelecer relações entre os sentidos e as significações de seus atos, posto o papel fundamental que tais condições desempenham na produção da consciência".

O professor, enquanto mediador do conhecimento científico com vistas a possibilitar aos alunos a apropriação das máximas qualidades humanas, como preconiza a Teoria Histórico-Cultural, concebe que para atingir os objetivos educacionais é inescusável compreender e realizar a mediação pedagógica.

\section{A formação do professor como subsídio para mediação do conhecimento}

Quando se discute a formação e a ação docente, é imprescindível abordar a questão da mediação como eixo central do trabalho realizado pelo professor. Inicialmente, para a compreensão da mediação pedagógica pressupõe-se o entendimento do referido conceito. Em termos genéricos, Oliveira (apud MARTINS 2012, p.9) define mediação como um processo de intervenção de um elemento intermediário numa relação; a relação deixa, então de ser direta e passa a ser mediada por esse elemento. Em Almeida, Oliveira e Arnoni (2007, p.1313) o conceito de mediação é concebido como

[...] fundamento de uma didática que compreende um método, uma metodologia e uma lógica, permitindo assim aos professores o acesso a um referencial teórico e operacional por meio do qual possam desenvolver um processo de ensino comprometido com a aprendizagem dos alunos. Isso porque a mediação encerra uma totalidade que articula método, metodologia e lógica, elementos centrais e necessários àquele processo. Assim, a mediação permite ao professor superar os tradicionais métodos de ensino que se fundamentam numa didática de cunho estritamente metodológico, sem a devida articulação da metodologia com o método e a lógica.

Nessa lógica, depreende-se que na mediação, o conteúdo, a forma e a lógica dialética se articulam num processo entre professor e aluno, o que contribui para efetivação do processo de ensino e aprendizagem. Em qualquer nível de escolarização, é desejável que aconteça a transposição do conhecimento cotidiano para o conhecimento científico e é impreterível a mediação do professor nessa trajetória. A dinâmica nesse processo é ilustrada 
por Martins (2012, p. 12) como salto em vara, antes o salto humano alcançava apenas pouco mais de 2 metros de altura, quando a vara foi inserida como "mediadora", o salto chegou a mais de 7 metros. Exemplificando a influência da mediação no resultado da ação.

O docente como mediador, planeja suas ações de forma intencional e inicia o seu trabalho antes mesmo do momento em que vai para sala de aula. Como referendam Almeida, Oliveira e Arnoni (2007, p. 20), a

[...] mediação é precedida de uma ação da qual somente o professor se ocupa ao realizar o planejamento da aula - com a seleção e preparo do conteúdo de ensino -, resultando, a seguir, no momento em que a aula se desenrola, na mediação estabelecida entre o professor, que realiza o ofício do ensino compreendido por nós como a relação que este desenvolve com o conhecimento -, e o aluno, que realiza a aprendizagem - por nós concebida como a relação entre ele e o conhecimento.

A produção da consciência no aluno percorre esse caminho e embora ele seja ativo nesse processo, não se trata de aprender sozinho, nesse sentido requer a intervenção docente. Em outras palavras, um professor atento ao seu processo de formação, embasado no método de análise que parte da síncrese à síntese como inacabado e em construção, e ainda, que fundamenta suas ações pedagógicas em concepções científicas afirmadas, poderá apresentar melhores condições para articular seus conhecimentos teóricos e instrumentais frente às demandas do seu trabalho educativo. Isso contribuirá para mobilizar o aluno a estabelecer relações com o que ele já sabe e atingir novas e mais complexas objetivações.

Ressalta-se que o papel do professor é proporcionar-lhe experiências mediadas pelo conhecimento, potencialmente humanizadoras. Ocorre que nos debates atuais, de acordo com Martins (2015), os problemas relacionados à educação restringem-se a qualidade da formação e da mediação do professor, e se desconsidera outros determinantes igualmente impactantes nesse contexto. Sobre isso a referida autora destaca que as

[...] complexas relações entre educação e sociedade - que cada vez mais têm colocado a escola a serviço da manutenção da ordem globalizante e neoliberal vigente em detrimento da promoção do desenvolvimento de seus membros, sejam eles alunos ou professores - diluem-se em análises que colocam a escola e o professor como vítimas do tempo e da organização social, que em sua estrutura política e econômica não é efetivamente questionada. Nesse sentido, acaba por não conferir devida ênfase à formação de indivíduos que possam modificar tais relações, bem como à construção e apropriação dos conhecimentos historicamente sistematizados. Desse modo, as mudanças aventadas no que tange à formação dos professores e ao trabalho docente correm um grande risco: converterem-se em estratégias de adaptação (MARTINS, 2015, p. 20). 
Sendo assim, as discussões não têm abordado a formação no sentido de refletir acerca de novas possibilidades para alterar esse quadro e enfatizar outro modelo formativo. Dessa forma secundariza-se a "finalidade emancipatória da educação", tanto a do educador quanto das futuras gerações. Por essa razão, levanta-se a premência de debater os processos formativos no que concerne a apropriação das "objetivações humanizadoras produzidas pelos homens histórica e socialmente, condição para sua humanização e consequente emancipação", bem como negar a perspectiva de formar o docente para adaptar-se as "estruturas sociais alienantes". (MARTINS, 2015, p.22-24).

Alguns movimentos enredados pelas esferas públicas tem buscado empobrecer a perspectiva do trabalho pedagógico retirando dele o que lhe é essencial, ou seja, o conhecimento, imprescindível para possibilitar "[...] a apropriação de formas de elevação acima da vida cotidiana [...], em direção ao humano-genérico" (MARTINS, 2015, p.21). É essa a finalidade principal da atividade educativa. $\mathrm{O}$ trabalho pedagógico consiste em articular essa finalidade, os conhecimentos científicos, bem como as metodologias pertinentes. Principalmente com base nesses pressupostos, devem ser organizados os cursos de formação do professor. Diante disso, trataremos de destacar a seguir os aspectos fundamentais no processo de formação do professor: o ensino e a aprendizagem.

\section{O processo indissociável de ensino-aprendizagem}

Verifica-se que o trabalho pedagógico nos cursos de formação do educador tem como cerne o "saber" desarticulado "do como" e "do que fazer", ocasionando um desajuste nas interações teórico-práticas das disciplinas e no processo de ensino e aprendizagem. Este problema é também reflexo da estruturação curricular do curso e do entendimento do significado do lugar que ocupa os conhecimentos elaborados na vida dos indivíduos. Estando equivocada essa ideia pode ocasionar prejuízos tanto ao que ensina como ao aluno que aprende. Um exemplo disso refere-se ao aluno que aprende um caminho sem uma direção certa de onde se deve chegar.

Um fator importante no processo de ensino e aprendizagem são as relações estabelecidas entre professor-conhecimento, essas, consequentemente serão refletidas tanto na atuação do professor como nas futuras práticas dos que estão em formação, uma vez que, dependendo do modelo apropriado poderão propiciar novos olhares para o processo de 
ensinar e aprender, considerando a categoria da totalidade na formação profissional e humana do sujeito. Com tal característica, o professor poderá fundamentar suas ações pedagógicas no sentido de pensar a elevação das capacidades do aluno no processo de sua aprendizagem.

O ensino é a atividade principal do professor, o que envolve uma atuação de se trabalhar com os conhecimentos elaborados possibilitando aos alunos a síntese dos mesmos com a finalidade de desenvolvimento, incremento das funções psicológicas superiores (sensação, percepção, emoção, linguagem, pensamento, memória etc.) no processo formativo. (VYGOTSKY, 1996).

É possível considerar que essa forma de atuação do professor em sala de aula articulase com a formação recebida durante a sua vida estudantil, principalmente no curso de graduação. Percebemos que um dos modelos de ensino que tem sido privilegiado na universidade, em especial nos cursos de formação de professores, é o ensino como transmissão cultural de conhecimento, o qual valoriza os conteúdos das diferentes disciplinas distantes do interesse dos alunos, sem conexão com a realidade educacional brasileira. No entanto, diferentes pesquisas na área denunciam o despreparo do professor baseado nesse modelo de ensino. Atualmente, a exigência social e educacional solicita que o professor, para atuar nas escolas brasileiras, necessariamente precisa ter a capacidade de lidar com o conhecimento que vai além da mera transmissão.

Diante desse quadro, os cursos de formação de professores precisam ser repensados. É importante, na reflexão sobre as reformulações destes cursos, a seguinte questão: "Qual deve ser o modelo de ensino que os cursos de formação de professores devem adotar para formar profissionais capazes de atuar de modo competente nas escolas brasileiras?". Para esclarecimento, quando utiliza-se a palavra competência, esta não se relaciona em absoluto ao caráter utilitário, refere-se ao significado de "Capacidade decorrente de profundo conhecimento que alguém tem sobre um assunto". ${ }^{7}$

O processo indissociável ensino-aprendizagem não deve vincular-se ou deter-se a mecanismos reproduzidos e automatizados, mas estender-se ao compromisso do profissional da educação - o professor - sujeito que visualize possibilidades a partir da sua atuação, de superação dos modelos de ensino mecanicistas para um ensino que contribua com as mudanças qualitativas sociais e educacionais, buscando práticas pedagógicas que auxiliem na articulação do ensino com a aprendizagem visando a produção da humanidade no sujeito. À vista disso, é preciso destacar que a prática docente é socialmente produzida, em que as 
diversas circunstâncias e relações que permeiam a vida do professor, influenciam e contribuem para efetivação da práxis.

Com isso, o educador formador de professores deve adotar o modelo de ensino baseado na relação dialética entre teoria e prática, assim, colaborará para a preparação de professores capazes de atuar no seu contexto real. O profissional capaz de refletir sobre seu trabalho antes, durante e após sua objetivação, terá melhores condições de agir para transformar o ensino.

O trabalho pedagógico desenvolvido na perspectiva da indissociabilidade teoria e prática, possibilitará a formação de docentes mais conscientes do seu papel, com condições de ler, de compreender e modificar o contexto escolar no qual está inserido. Esta transformação de que se fala baseia-se na crítica do conhecimento e da experiência, em que o educador poderá oferecer a sua contribuição por meio do seu trabalho pedagógico.

Por conseguinte, a função dos educadores dos cursos de formação de professores será a de mediadores entre os futuros docentes e a cultura elaborada historicamente. Nesse sentido, a prática pedagógica constituirá o seu campo de trabalho, bem como de seu aprendizado contínuo.

Nesse sentido, o curso de formação de professores deve estimular os futuros profissionais da educação a se engajarem na construção do ato educativo, para que sejam capazes de enfrentar situações de ensino-aprendizagem mais complexas na sua prática pedagógica, pois tal prática requer qualificação docente com conhecimento aprofundado, não só no que se refere às questões educacionais, mas também questões externas que influenciam o seu funcionamento.

\section{Considerações finais}

A partir do exposto nesse estudo avalia-se que um processo de formação deve levar em consideração a análise dos modelos postos de padronização e mecanicismo na possibilidade de superação da dicotomia teoria e prática e da sua forma racionalista. Sabe-se que uma prática desvinculada de pressupostos teóricos esvazia-se de suas finalidades e pode apresentar como consequência sérios prejuízos à efetivação do processo ensinoaprendizagem. Assim sendo, verifica-se no ambiente escolar a presença dos chamados modismos teóricos, o acolhimento das diretrizes governamentais sem os devidos questionamentos críticos, bem como a dependência desses educadores do suporte que representa para eles o livro didático, tornando-o a base do processo pedagógico, 
desqualificando a função docente. O professor nesse contexto precisa pensar uma formação de natureza científica, intencional e sistematizada no mais elevado nível de qualificação, em que a indissociabilidade teoria e prática seja o eixo norteador no seu verdadeiro significado - a práxis.

Conclui-se, que o curso de formação de professores deve suscitar nos futuros docentes a construção do trabalho educativo de maneira qualitativa, soma-se a isso, capacitá-los a mediar situações de ensino-aprendizagem mais complexas na sua prática pedagógica, rompendo com os imediatismos que engessam a educação no sentido amplo. Tal prática requer esforço, além de conhecimentos aprofundados, tanto sobre as questões educacionais quanto a questões externas que reverberam em seu funcionamento. Nessa lógica estabelece-se a premência do professor se engajar no processo de formação, apropriando-se dos fundamentos da atividade docente, visualizando alternativas para a formação e o trabalho educativo.

A partir das perspectivas estudadas no âmbito dessa investigação, constata-se que nos cursos de formação de professores é premente a superação da dissociação entre conteúdo e forma, constituindo-se esse um dos dilemas dos programas formativos. O professor, enquanto mediador do conhecimento científico com vistas possibilitar em seus alunos a apropriação das máximas qualidades humanas deve ser formado em condições que lhe possibilitem o desenvolvimento do raciocínio crítico acerca do seu trabalho, para poder direcioná-lo conforme a lógica dialética visando a transformação do quadro social vigente ao invés de adaptar-se ao que está posto pela ideologia dominante.

Avalia-se a partir do exposto, que a lógica dialética proporciona modos de pensar a atividade educativa de maneira criadora e revolucionária. Nesse sentido, o trabalho pedagógico consiste em articular os conhecimentos científicos, com as metodologias pertinentes ao contexto de ensino e aprendizagem. Principalmente, quando a base do trabalho educativo se pauta em pressupostos teórico metodológicos em que devem ser organizados os cursos de formação do professor tanto inicial como continuada.

\section{REFERÊNCIAS}

ALMEIDA, J. L. V. de. OLIVEIRA, E. M. de. ARNONI, M. E. B. Mediação dialética na educação escolar: teoria e prática. Edições Loyola, São Paulo, 2007.

DICIONÁRIO online de português. Disponível em: https://www.dicio.com.br/competencia/. Acesso em 24 mar 2018. 
FREITAS, L. C. de. Conseguiremos escapar ao neotecnicismo? In: SOARES, M. B. et al. Escola básica. Campinas: Papirus/Cedes: São Paulo: Ande/Anped, 1992.

GASPARIN, J. L. Uma didática para a Pedagogia Histórico-Crítica. Campinas, SP: Autores Associados, 2002.

KOSIK, K. Dialética do concreto. Rio de Janeiro: Paz e Terra, 1995.

MARTINS, L. M. DUARTE, N. (Org.) Formação de professores: limites contemporâneos e alternativas necessárias. Apoio técnico Ana Carolina Galvão Marsiglia. - São Paulo: Cultura Acadêmica, 2010.

MARTNS, L. M. A formação social da personalidade do professor: um enfoque vigotskiano. $2^{\text {a }}$ ed. Campinas, SP: Autores Associados, 2015.

MARTINS, O. B.; MOSER, A. Conceito de mediação em Vygotsky, Leontiev e Wertsch. Revista Intersaberes, v. 7, n. 13, 2012.

SAVIANI, D. Formação de professores: aspectos históricos e teóricos do problema no contexto brasileiro. Revista Brasileira de Educação, v. 14, n. 40, jan./abr. 2009.

SAVIANI, D. Pedagogia histórico-crítica: primeiras aproximações. 6. ed. Campinas: Autores Associados, 1997.

SILVA, V. P. da. Formação de professores na perspectiva da filosofia da práxis: quem educa o educador? In: MILLER, Stela; BARBOSA, Maria Valéria; MENDONÇA, Sueli Guadalupe de Lima. (orgs.). Educação e Humanização: as perspectivas da teoria histórico-cultural. Jundiaí, Paco Editorial: 2014.

VAZQUEZ, A. S. Filosofia da práxis. Rio de Janeiro: Paz e Terra, 1968.

VYGOTSKY, L. S. Pensamento e Linguagem. Rio de Janeiro: Martins Fontes, 1998.

\section{Como referenciar este artigo}

BARROS, Marta Silene Ferreira; PASCHOAL, Jaqueline Delgado; VICENTINI, Dayanne Jacqueline; FRANÇA DE ALMEIDA, Daniele Ana; FERREIRA, Letícia; BARROS, Priscila Cordeiro Soares. A relação Teoria e Prática na formação docente: condição essencial para o trabalho pedagógico. Revista Ibero-Americana de Estudos em Educação, Araraquara, v. 15 , n. $1, \quad$ p. 305-318, jan./mar. 2020. e-ISSN: 1982-5587. DOI: https://doi.org/10.21723/riaee.v15i1.13303

Submetido em: 10/12/2018

Revisões requeridas: 20/05/2019

Aprovado em: 19/08/2019

Publicado em: 02/01/2020 